\title{
Investigation of new additives to reduce the fume emission of bitumen during Asphalt Concrete Processing
}

\author{
Paolino Caputo ${ }^{1, *}$, Giuseppe Antonio Ranieri ${ }^{1}$, Nicolas Godbert ${ }^{2}$, Iolinda Aiello ${ }^{2}$, Antonio Tagarelli ${ }^{3}$ \\ and Cesare Oliviero Rossi ${ }^{1, *}$ \\ ${ }^{1}$ Dipartimento di Chimica e Tecnologie Chimiche, Università della Calabria, Cubo 14/D, Arcavacata di \\ Rende (CS), 87036, Italy. tel./fax. +39 0984492045 \\ ${ }^{2}$ MAT-INLAB (Laboratorio di Materiali Molecolari Inorganici), LASCAMM CR-INSTM, Unità INSTM \\ della Calabria, Dipartimento di Chimica e Tecnologie Chimiche, Università della Calabria, Cubo 14/C, \\ Arcavacata di Rende (CS), Italy \\ ${ }^{3}$ Dipartimento di Chimica e Tecnologie Chimiche, Università della Calabria, Cubo 12/C, I-87036, Arcavacata \\ di Rende (CS), Italy
}

\begin{abstract}
Pavement materials play an important role in overall pavement sustainability including material acquisition processing, and transportation. The main objective of the present study is to evaluate the effectiveness of new additives, to reduce bitumen's fume emission expelled into the atmosphere, during the processing of asphalt concrete. The new additives act by trapping bitumen's volatile substances avoiding their release at high temperatures. In this paper, we have been tested the performance of 2 types of mesoporous silica-based additives (AntiSmog 1 and AntiSmog 2). The idea of using these additives to reduce the emission of fumes in bitumen has been submitted as a patent. To quantify and characterize the emitted fumes, thermogravimetry (TGA) and gas chromatography-mass spectrometry (GC-MS) technique have been used. Dynamic Shear Rheology (DSR) has been used to check the rheological properties and the possible sedimentation issues that could occur after the addition of the additives.
\end{abstract}

Keywords: fume; bitumen; mesoporous; thermogravimetry (TGA); gas chromatography-mass spectrometry (GC-MS).

\section{Introduction}

Most definitions of sustainability begin with that issued by the World Commission on Environment and Development (WCED) in 1987: "Sustainable development is a development that meets the needs of the present without compromising the ability of future generations to meet their own needs." Moreover, sustainability is often described as a quality that reflects the balance of three primary components: economic, environmental, and social impacts ${ }^{1}$.

"Sustainable" in the context of pavements refers to system characteristics that encompass a pavement's ability to:

-Achieve the engineering goals for which they were constructed.

- Preserve and (ideally) restore surrounding ecosystems.

- Use financial, human, and environmental resources economically.

*Corresponding author: Paolino Caputo, Cesare Oliviero Rossi

Email address: paolino.caputo@unical.it, cesare.oliviero@unical.it

DOI: http://dx.doi.org/10.13171/mjc74181107-rossi
- Meet human needs such as health, safety, equity, employment, comfort, and happiness.

All stakeholders in the pavement community from owner/agencies to designers, and from material suppliers to contractors and consultants are embracing the need to adopt more sustainable practices in all

aspects of their work, and are continually seeking the latest technical information and guidance available to help improve those practices ${ }^{2}$.

Low consumption of energy for production and construction, low emission of greenhouse gases or fumes and conservation of natural resources help to make asphalt the environmental pavement of choice ${ }^{3-5}$. However, the ever-increasing pavement's loads and the needs for using modified binders and additives to coup the problem of heavy-duty pavements has led to both environmental and economic concerns.

In particular, this paper intends to show the benefits of new additives on the emission of bitumen

Received October 11, 2018

Accepted October 23, 2018

Published November 7, 2018 
fumes and a methodology to check their chemical composition.

Bitumen is a soft multicomponent material issued from the petroleum cracking industry as a residual side-product ${ }^{6}$. For this reason, its chemical composition is randomly composed of various substances also including volatile and toxic chemicals that are subject to be easy release into the ambient during the processing step, in particular during the layering of bitumen onto the roads. Not only these substances can be toxic for the environment, but they certainly are toxic for the workers that are processing bitumen as pure material or in mixtures such as asphalt concrete ${ }^{7}$.

Indeed, each time bitumen is heated either for road paving or to manage and transport it in high quantity, risks of chemicals release are present. Up to now, additives are used in asphalt concrete with the main aim to decrease the temperature of asphalt processing, thus limiting the emission of possible toxic fumes of volatile components ${ }^{8-10}$. For this reason, there is a need to devise new additives that could be injected into bitumen to reduce the emission of toxic fumes ${ }^{11}$, without adversely affecting the rheological properties of the resulting concrete. To this regard, we used two different additives, both silica based mesoporous powders (AntiSmog 1 and AntiSmog 2) able to entrap volatile fumes.
Many researchers described environmental applications of mesoporous silica that have permitted their use in a diverse range of applications from biosensors ${ }^{12}$, biomedicine ${ }^{13}, 14$, drug delivery 15 , pollutants removal 16 to optical devices ${ }^{17}$. However, this article will focus on the application of mesoporous silica primarily for adsorption of organic pollutants from bitumen.

In order to quantify and identify the volatile substances released during bitumen processing, thermogravimetry (TGA) 18 and gas chromatography-mass spectrometry (GC-MS) techniques ${ }^{19}$ were used along with Dynamic Shear Rheology (DSR) to check the rheological properties of the bitumen after the insertion of specific additives. The use of additives as powder state requires an integrated experimental approach to check the rheological properties of the resulting material and the eventual sedimentation that could occur within the thus formulated concrete. To this purpose shear dynamic experiments were done.

\section{Materials and Methods}

The bitumen used in this work was kindly supplied by Loprete Costruzioni Stradali (Italy). It was produced in Italy but the crude oil was coming from Saudi Arabia. Its penetration grade was 50/70. Data are shown in Table 1:

Table1. Properties of Pristine bitumen (PB) and Modified Bitumen (BM).

\begin{tabular}{|l|l|l|c|c|}
\hline & & PB & BM1 - 1\% & BM2 - $1 \%$ \\
\hline $\mathrm{PN}(0.1 \mathrm{~mm})$ Penetration depth $\pm \mathbf{1}$ & ASTM D 946 & $\mathbf{6 0}$ & $\mathbf{5 6}$ & $\mathbf{5 4}$ \\
\hline $\mathrm{R} \& \mathrm{~B}\left({ }^{\circ} \mathrm{C}\right)$ Softening point $\pm \mathbf{1}$ & ASTM D 36 & $\mathbf{5 1}$ & $\mathbf{5 0 . 4}$ & $\mathbf{5 2 . 2}$ \\
\hline $\mathrm{X}_{\mathrm{A}}(\mathrm{wt} \%)$ Asphaltene content $\pm \mathbf{0 . 5}$ & C.O. Rossi et al. $[6]$ & $\mathbf{2 6 . 8}$ & $\mathbf{2 7 . 1}$ & $\mathbf{2 7 . 3}$ \\
\hline $\mathrm{TR}\left({ }^{\circ} \mathrm{C}\right)$ Transition temperature $\pm \mathbf{0 . 1}$ & & $\mathbf{6 8 . 0}$ & $\mathbf{6 5 . 8}$ & $\mathbf{6 9 . 5}$ \\
\hline
\end{tabular}

Additives:

AntiSmog1 (additive 1) and AntiSmog2 (additive 2 ) additives were developed by the academic Spin-Off (Kimical SRL) of the University of Calabria, commercial named Kimical NoSmogA and Kimical NoSmogB respectively, following reported procedures to synthesize mesoporous silica in basic conditions (AntiSmog1) and in acid conditions (AntiSmog2). All technical information can be obtained by Kimical SRL.

In general, the mesoporous silica materials can be characterized in terms of pore diameter, surface area and pore volume ${ }^{20}$. The two additives used in the present work display different porosities.

Details of the preparation and the use of these additives to reduce the emission of toxic fumes from hot bitumen are contained in the Italian Patent (n.102016000041219). Authors of the patent are available for further feedback.

Both additives AntiSmog1 and AntiSmog2 were added to the investigated bitumen, under vigorous stirring (600 RPM) at the temperature of $150^{\circ} \mathrm{C}$ and the stirring was maintained for 30 minutes. Cooling to room temperature allowed obtaining the bitumen mixtures BM1 and BM2 respectively. Different concentrations of additives were studied ranging from 1 to $10 \% \mathrm{w} / \mathrm{w}$. The heating temperature $\left(150^{\circ} \mathrm{C}\right)$ was chosen below the smoke point of the used bitumen to allow a homogeneous mixture under stirring without emission of fumes. The same experimental condition was applied to the neat bitumen (exposed to the same temperature and stirring treatment before analysis) in order to produce the reference sample called "pristine bitumen", PB, throughout the article. With this reference, it will be possible, throughout the whole study, to directly assert that the observed changes in properties are related to the addition of the additives and are not due to the pre-heating period used for the preparation of the samples.

\section{Thermogravimetric measurements:}

The thermogravimetric analysis allows measuring accurately the weight loss of the sample during the linear increase of temperature. 
The thermogravimetric studies were performed on a Perkin-Elmer TGA-6 instrument. Analyzed samples consisted of $c a .3 \mathrm{mg}$ of samples taken at the end of the $30 \mathrm{~min}$ period of stirring as described above. Analyses were performed from $100^{\circ} \mathrm{C}$ to $300^{\circ} \mathrm{C}$ at a temperature scan rate of $2^{\circ} \mathrm{C} / \mathrm{min}$.

\section{GC-MS analysis:}

The GC-MS technique represents a reliable analytical tool because of the high separation efficiency of gas chromatographic technique and the great sensitivity and specificity of mass spectrometry. This approach represents a very specific analytical methodology that allows for the reduction of interferences and then the improvement of the reliability of the entire method.

GC-MS analyses were performed using a TSQ Quantum GC (Thermo Fischer Scientific) system constituted by a triple quadrupole mass spectrometer (QqQ) Quantum and a TRACE GC Ultra.

The capillary column was $30 \mathrm{~m} \times 0.25 \mathrm{~mm}$ i.d., $0.25 \mu \mathrm{m}$ film thickness Thermo TR-5MS (95\% polydimethylsiloxane, $5 \%$ polydiphenylsiloxane).

$4 \mathrm{~g}$ of bitumen mixture was directly weighted in a suitable vial $(30 \mathrm{~mL})$. After $300 \mu 1$ of internal standard (Phenanthrene-d10) solution at $133 \mathrm{mg} \mathrm{l}^{-1}$ were added and the vial was crimped and maintained in an oil bath at $160-170{ }^{\circ} \mathrm{C}$ for 30 minutes. Solidphase microextraction (SPME) extraction was performed with a $100 \quad \mu \mathrm{m}$ PDMS (polydimethylsiloxane) fiber in headspace immersion mode for $15 \mathrm{~min}$, and the extracted analytes were thermally desorbed by introducing the fiber into the injector set at $280{ }^{\circ} \mathrm{C}$ for $10 \mathrm{~min}$. The $\mathrm{GC}$ oven temperature was initially held at $70{ }^{\circ} \mathrm{C}$ for $10 \mathrm{~min}$, then ramped at $20{ }^{\circ} \mathrm{C} \mathrm{min}-1$ to $200{ }^{\circ} \mathrm{C}$ and held at this temperature for $1.5 \mathrm{~min}$, then ramped again at $20^{\circ} \mathrm{C}$ $\min ^{-1}$ to $260{ }^{\circ} \mathrm{C}$ and maintained at this temperature for further $2 \mathrm{~min}$ before being finally increased at $20^{\circ} \mathrm{C}$ $\mathrm{min}^{-1}$ to $340^{\circ} \mathrm{C}$ for 5 minutes. The carrier gas was helium at $1.2 \mathrm{ml} \mathrm{min}^{-1}$ of purity $99.999 \%$. For SPME analyses, a Thermo PTV straight Liner $0.75 \mathrm{~mm} \times$ $2.75 \mathrm{~mm} \times 105 \mathrm{~mm}$ was used as GC inlet liner. The QqQ mass spectrometer was operated in electron ionization (EI) in full scan mode.

\section{Dynamic Shear Rheology:}

Dynamic Shear Rheological (DSR) measurements on bitumen samples were carried out using a controlled shear stress rheometer (SR5, Rheometric Scientific, USA) equipped with a parallel plate geometry (gap $2 \mathrm{~mm}$ and diameter $\phi=25 \mathrm{~mm}$ within the temperature range $25-150{ }^{\circ} \mathrm{C}$, while gap 2 and diameter $\phi=8 \mathrm{~mm}$ from 25 to $-30^{\circ} \mathrm{C}$ ). The Peltier system $\left( \pm 0.1^{\circ} \mathrm{C}\right)$ was used for temperature control.

Rheological dynamic experiments were performed within the linear viscoelastic region where rheological properties are independent of the amplitude of applied load and are the only function of the microstructure of material ${ }^{21}$. Aimed at investigating viscoelastic properties of the bitumen and phase transition, temperature ramp tests were performed at $1 \mathrm{~Hz}$ with heating rate $1^{\circ} \mathrm{C} / \mathrm{min}$ and applying the proper stress values to guarantee linear viscoelastic conditions (previously determined by stress sweep tests) at all tested temperatures. More details about the mechanical characterization can be found elsewhere ${ }^{22}$.

\section{Sedimentation tests:}

A tuben test procedure was performed to determine the sedimentation phenomenon of investigated samples.

The Tuben Test procedure was performed to determine the tendency of a powder asphalt modifier to separate from the bitumen during static storage at a controlled temperature. If a modified bitumen shows a tendency to separate during storage, this must be taken into account either by providing some sort of agitation or stirring or by reformulating the binder. The test procedure was conducted in according to EN13399 standard (Standard Practice for Determining the Separation Tendency of Polymer from Polymer Modified Asphalt) and is fully described in Oliviero Rossi et al. ${ }^{23}$

\section{Results and Discussion}

Thermogravimetric analysis of all prepared samples PB, BM1 and BM2 at various concentration content of additives were performed at $100^{\circ} \mathrm{C}$ starting temperature, at $2^{\circ} \mathrm{C} / \mathrm{min}$ temperature scan rate ${ }^{24}$.

Special attention has been paid to the weight loss occurring between $140^{\circ} \mathrm{C}-200^{\circ} \mathrm{C}$ temperature range, which is usually used to process the bitumen. Remarkably, concerning the pristine bitumen PB, both additives were able to delay and therefore reduce the weight loss of the bitumen.

Indeed, already at $100^{\circ} \mathrm{C}, \mathbf{P B}$ shows slow but constant weight loss up to $250^{\circ} \mathrm{C}$. At this temperature, the $2 \%$ of weight loss is registered for $\mathbf{P B}$, while both BM1 and BM2 samples have constant weight up to $170^{\circ} \mathrm{C}$, even with additive concentrations as low as $1 \% \mathrm{w} / \mathrm{w}$.

Fig. 1 shows, as an example, the superimposition of TGA thermograms registered for BM1-1\% w/w BM1-5\% w/w, BM1-10\% w/w together with the TGA thermogram registered for the pristine bitumen sample PB.

We focus our characterization only to the sample with $1 \%$ of the additive. Considering that within the temperature range $140-200^{\circ} \mathrm{C}$, the samples containing 1,5 and $10 \%$ of additive, show the similar trends (only slight differences are observable in the TGA analysis), it was clear that $1 \%$ of additive is enough to ensure a good performance regarding fumes emission 
reduction. Consequently, the objective of such approach is to minimize both the quantity of additive(s) and the possible change in physicalchemistry properties of the resulting mixture compared to $\mathrm{PB}$ and also to minimize the cost of final modified bitumen.
In order to check the performances of the additives in trapping capacity of volatile fumes, isothermal TGA measurements have been performed at $200^{\circ} \mathrm{C}$, until a constant weight of the sample was recorded (around $40 \mathrm{~min})^{25}$.

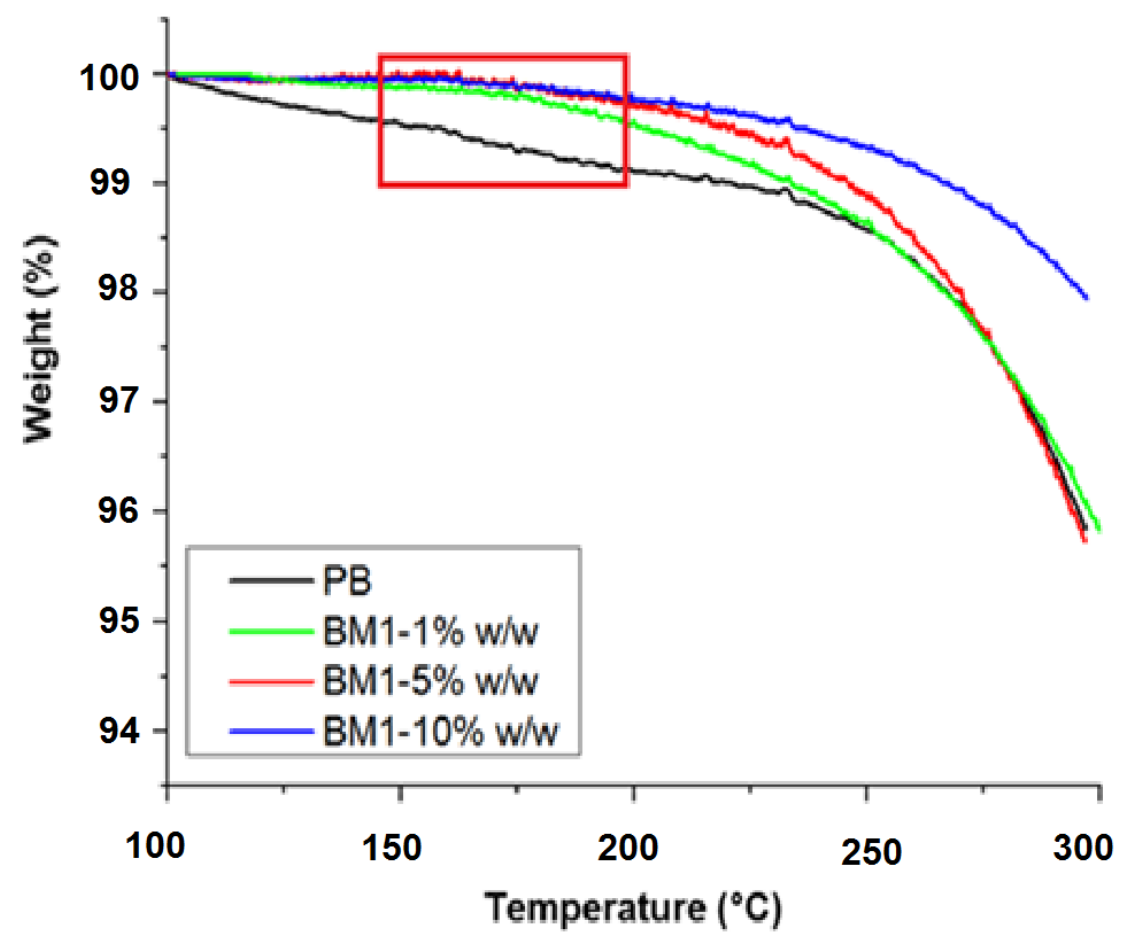

Figure 1. Thermograms of PB, BM1-5\% w/w and BM1-10\% w/w. The red inset shows the temperature window typically for the bitumen and pavement processing.

In Fig. 2 and Table 2 data of $\%$ weight loss obtained over time required to reach a constant weight are reported. All samples reach a constant value of loss weight approximately at the same time.
For samples, BM1-1\% w/w and BM2-1\% w/w smaller weight loss were registered when compared to $\mathbf{P B}$, consistent with less quantity of fume released.

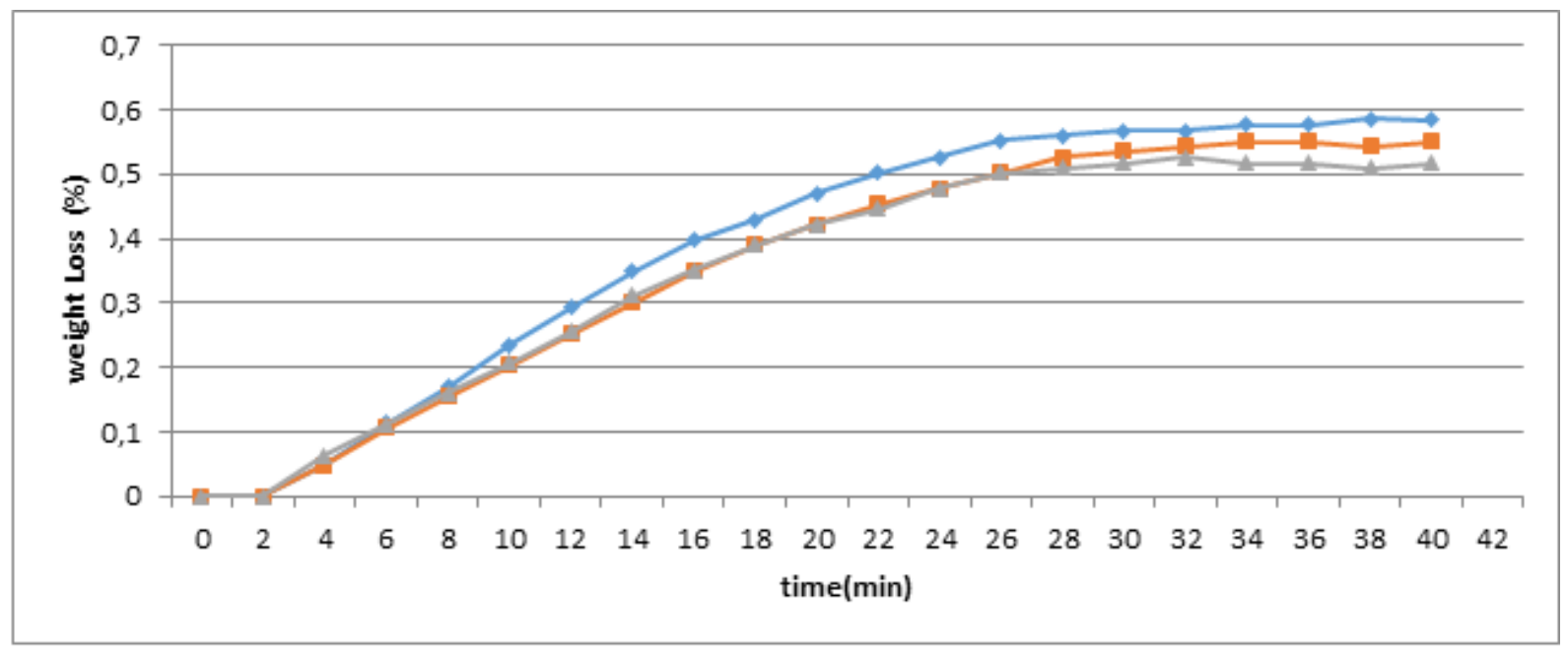

Figure 2. Additive performances in fume trapping at $200^{\circ} \mathrm{C}(\multimap$ Pristine Bitumen; - BM1-1\% w/w;

$$
\rightarrow \text { BM2-1\% w/w }
$$


Table. 2 Additive performances in fume trapping at $200^{\circ} \mathrm{C}$.

\begin{tabular}{|l|l|l|}
\hline Sample & Weight Loss (\%) & Fume released (\%) \\
\hline Pristine Bitumen (PB) & 0.560 & 100.0 \\
\hline BM1-1\%w/w & 0.527 & 94.1 \\
\hline BM2-1\%w/w & 0.510 & 91.7 \\
\hline
\end{tabular}

It is worth noticing that the reducing in fume emission resulting from the use of the two additives are very similar (curves are almost overlapped). Furthermore, the modified bitumens show a delay in the fume emission. Finally, the final weight loss is lower for both BM1 and BM2 samples concerning PB.

To check the efficiency in fume trapping of the two additives BM1 and BM2, GC-MS analyses of the emitted fumes were performed in order to identify their chemical content ${ }^{26}$. The fume released at $160^{\circ}-170^{\circ} \mathrm{C}$ by the pristine bitumen sample $\mathbf{P B}$, and the additive containing samples BM1-1\% w/w and BM2-1\% w/w were investigated/profiled. Specifically, the fumes emitted after $30 \mathrm{~min}$ from sealed samples kept at $160^{\circ} \mathrm{C}-170^{\circ} \mathrm{C}$ were analyzed by SPME technique ${ }^{27}$.

A PDMS fiber was inserted in the headspace through the rubber disk of a sealed vial and exposed to the generated fumes for 15 minutes allowing the easy and rapid extraction of analyses which were immediately desorbed into the injector of the gas chromatography system.

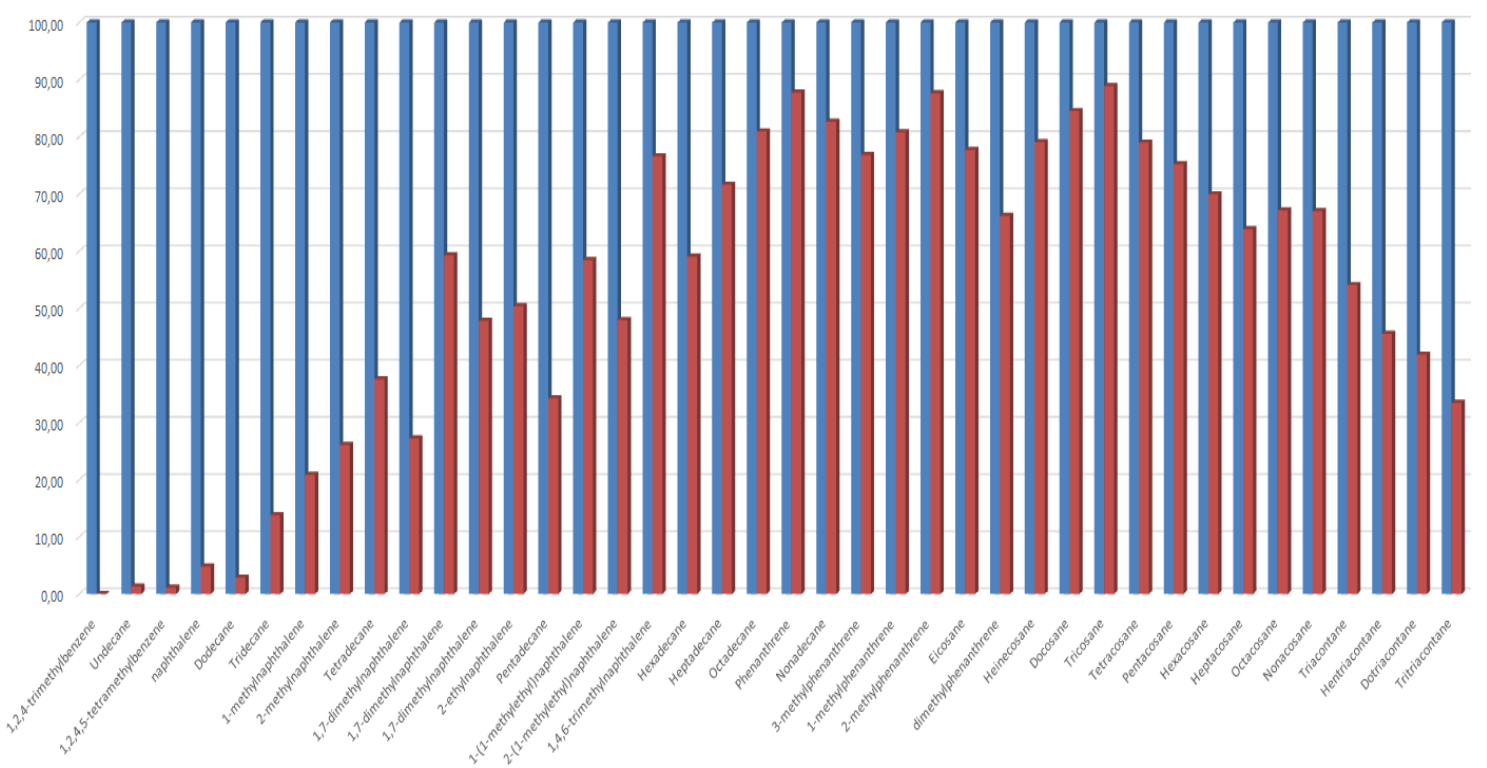

a. PB -BM1-1\%w/w

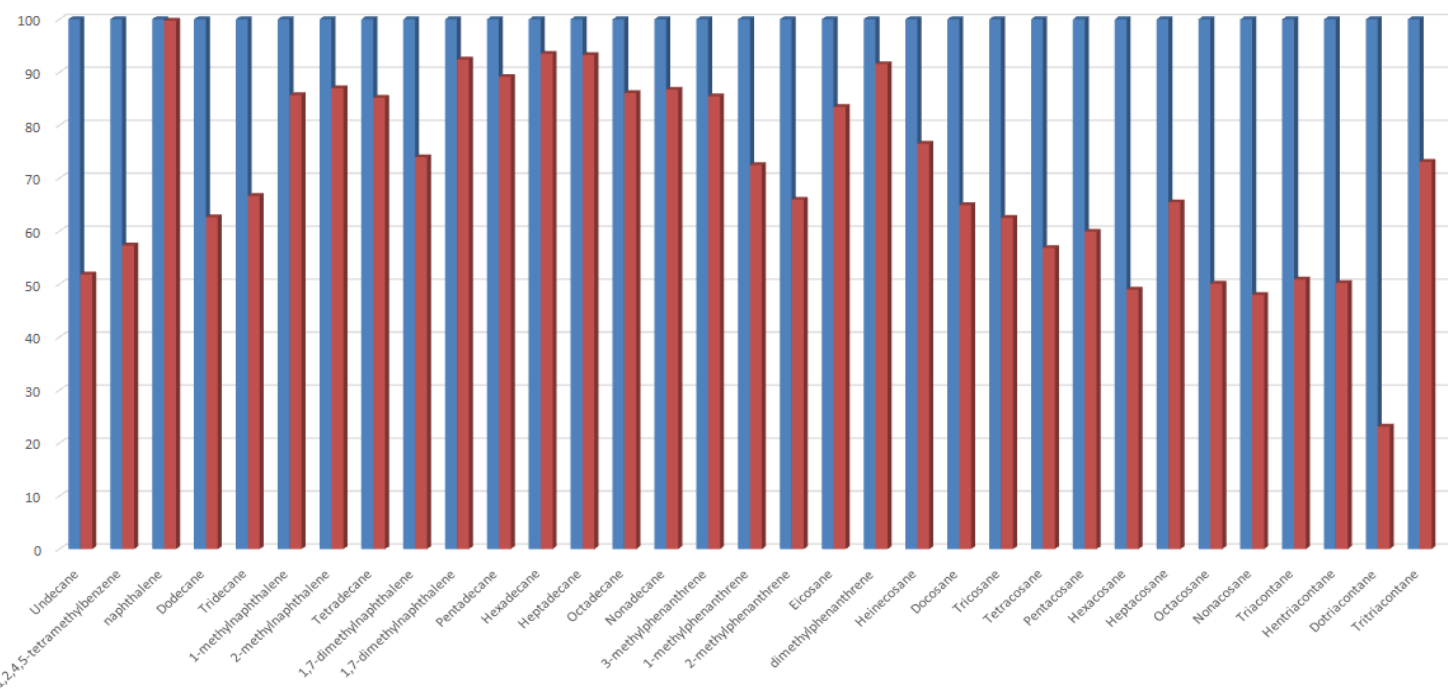

b. $\mathrm{PB}-\mathrm{BM} 2-1 \% \mathrm{w} / \mathrm{w}$

Figure 3. Selectivity of the additives towards the trappings of the chemicals present in the generated fumes of bitumen. 3a) comparison between PB and BM1-1\% w/w, 3b) comparison between PB and BM2-1\% w/w. 
In Fig.3, the performances of both additives AntiSmog1 (Fig.3a) and AntiSmog2 (Fig.3b) are shown. Responses were normalized taking into account amounts in PB as $100 \%$ for each analysis. These results highlight the different selectivity of the two additives towards the different chemicals contained in the generated fumes. The additive BM1 is indeed more efficient in the trapping of the smallest volatile chemicals, present in the released fumes as well as the largest ones, while the additive BM2 is more active towards the middle-size chemicals. These results confirm that the performance of the additives strongly depends on the porosity of the mesoporous silica. Thus, both additives display complementary behavior in trapping volatile chemicals avoiding their release into the fumes emitted during bitumen processing. This behavior must be correlated to the difference in the porosity of the two additives. The gas molecules passively approach the mesoporous silica surface and by slow diffusion are physically absorbed and entrapped within the pores through van der Waals

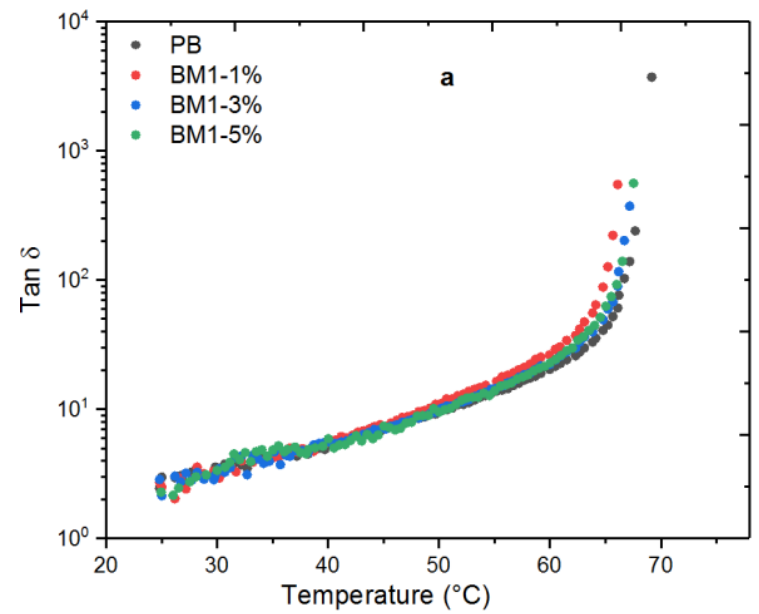

forces (dipole-dipole interactions and London dispersion forces). Hence, the difference in pore diameter between the two additives used could explain their difference in selectivity towards specific molecules.

In order to check the integrity of physicochemical properties of the bitumen upon addition of BM1 and BM2, DSR studies were performed. Remarkably, the rheological properties of the bitumen upon increase of additive 1 and 2, up to 5 $\% \mathrm{w} / \mathrm{w}$ are maintained. As an example, we report data for AntiSmog 1 (AntiSmog 2 showed similar rheological behavior). No significant difference has indeed been observed among samples. In the next graphs is possible to observe that the rheological curves obtained at low $\left(25^{\circ} \mathrm{C}\right.$ to $\left.-30^{\circ} \mathrm{C}\right)$ and high $\left(25^{\circ} \mathrm{C}\right.$ to $\left.80^{\circ} \mathrm{C}\right)$ temperature range for the samples prepared with additive 1 are comparable with the ones obtained for the $\mathbf{P B}$ and results are reported in Fig. $4^{28,29}$.

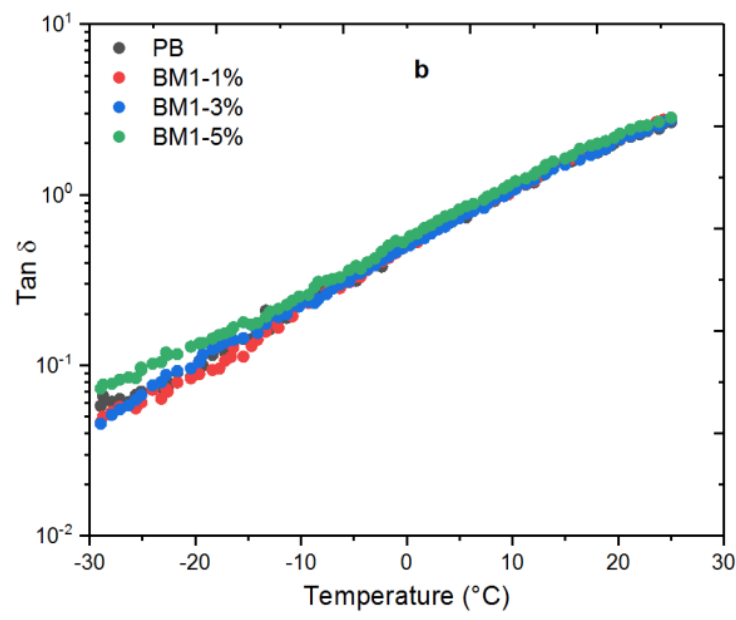

Figure 4. Rheological properties of pristine bitumen and Additive 1 containing mixtures. a) high temperature range $\left(25^{\circ} \mathrm{C}\right.$ to $\left.80^{\circ} \mathrm{C}\right)$, b) low temperature range $\left(25^{\circ} \mathrm{C}\right.$ to $\left.-30^{\circ} \mathrm{C}\right)$.

Finally, the possible sedimentation phenomenon induced by additives was checked by Tuben Tests. The investigation method was performed according to the EN-13399 standard (Standard Practice for Determining the Separation Tendency of Polymer from Polymer Modified Asphalt) ${ }^{23,30}$. Indeed, bitumen, being a soft material, can present a risk of sedimentation when additives in powder are added to it.

Both additives do not present sedimentation phenomena as can be observed as an example for
AntiSmog 1 at various concentrations. Indeed, the sedimentation tests were done at three different concentrations $(1 \%, 3 \%$ and $5 \% \mathrm{w} / \mathrm{w})$. The transition temperature of each sample was determined through DSR $^{31,32}$ and the results between the upper part and the downer part of the examined mixtures were compared and presented in Tab.3. Noteworthy in our case, none of the samples containing additives show sedimentation during the time of the experiment, indeed, no significant difference in temperature were registered between the different observed parts.

Table 3. Temperature difference between upper and downer parts of the sedimentation tubes.

\begin{tabular}{|l|l|}
\hline Sample & $\Delta\left({ }^{\circ} \mathrm{C}\right)$ \\
\hline BM1-1\%w/w & 1,1 \\
\hline BM1-3\%w/w & 0.3 \\
\hline BM1-5\%w/w & 0.5 \\
\hline
\end{tabular}




\section{Conclusions}

This article presents the performance of the new additives to reduce the fumes generated during the processing of Asphalt concrete. The thermogravimetric studies showed the efficiency of additives towards the trapping of toxic volatile chemicals contained in bitumen, while the GC-MS analysis allowed identifying the compounds more specifically trapped by the additives highlighting the different molecular selectivity between them.

DSR studies allows checking the integrity of the physicochemical properties of the resulting mixture and DSR measurements were also employed to check eventual sedimentation phenomena that could occur upon addition of the selected additives.

\section{Patents}

An Italian patent has been filed on April, 21, 2016 (\#102016000041219), untitled “ANTIFUMO PER BITUME E SUOI DERIVATI" Inventors: Giuseppe Antonio Ranieri, Cesare Oliviero Rossi, Paolino Caputo, Nicolas Godbert, Andrea Pagliuso, Haris Kaljaca. Applicant: University of Calabria, Italy and Kimical s.r.l.

\section{References}

1- M.W. Bardeesi, Y. Attallah, Economic and environmental considerations for pavement management systems, European Scientific Journal, 2015, 11, No.29.

2- K.J. Kowalski, J. Król, P. Radziszewski, R. Casado, V. Blanco, D. Pérez, V.M. Viñas, Y. Brijsse, M. Frosch, D.M. Le, M. Wayman, Eco-friendly materials for a new concept of asphalt pavement, Transportation Research Procedia, 2016, 14, 3582-3591.

3- B. Peng, C. Cai, G. Yin, W. Li, Y. Zhan, Evaluation system for $\mathrm{CO} 2$ emission of hot asphalt mixture, Journal of Traffic and Transportation Engineering (English edition), 2015, 2 (2), 116 - 124.

4- 4. P.Q Cui, S.P. Wu, Y. Xiao, M. Wan, P.D. Cui. Inhibiting Effect of Layered Double Hydroxides on the Emissions of Volatile Organic Compounds from Bituminous Materials, Journal of Cleaner Production, 2015, 108, 987-991.

5- P.Q. Cui, S.P. Wu, Y. Xiao, H.H. Zhang. Study on the deteriorations of bituminous binder resulted from volatile organic compounds emissions, Construction and Building Materials, 2014, 68, 644-649.

6- C. Oliviero Rossi, P. Caputo, G. De Luca, L. Maiuolo, S. Eskandarsefat, C. Sangiorgi, 1H-NMR Spectroscopy: A Possible Approach to Advanced Bitumen Characterization for Industrial and Paving Applications, Applied Science, 2018, 8, 229.
7- $\quad$ L. Gate, C. Langlais, J.C. Micillino, H. Nunge, M.C. Bottin, R. Wrobel, S. Binet, Bitumen fume-induced gene expression profile in rat lung, Toxicology and Applied Pharmacology, 2006, 215, 83-92.

8- Fall 12-17-2010 Effects of Warm-mix Asphalt Additives on Asphalt Mixture Characteristics and Pavement Performance Jun Zhang University of Nebraska-Lincoln, junzhangnj126@huskers.unl.edu.

9- Y. Xiao, M. Wan, K.J. Jenkins, S.P. Wu, P.Q. Cui. Using Activated Carbon to Reduce the Volatile Organic Compounds from Bituminous Materials, Journal of Materials in Civil Engineering, 2017, 29(10), P: 04017166.

10- P.Q Cui, H.G. Zhou, C. Li, S.P. Wu, Y. Xiao. Characteristics of Using Layered Double Hydroxides to Reduce the VOCs from Bituminous Materials, Construction and Building Materials, 2016, 123, 69-77.

11- M. Posniak, Polycyclic Aromatic Hydrocarbons in the Occupational Environment during Exposure to Bitumen Fumes, Polish Journal of Environmental Studies, 2005, 14(6), 809-815.

12- M. Hasanzadeh, N. Shadjou, M. de la Guardia, M. Eskandani, P. Sheikhzadeh, Mesoporous silica-based materials for use in biosensors, Trends in Analytical Chemistry, 2012, 33, 117 129.

13- R. Narayan, U.Y. Nayak, A.M. Raichur, S. Garg, Mesoporous silica nanoparticles: A comprehensive review on the synthesis and recent advances, Pharmaceutics, 2018, 10, 118; doi: 10.3390 .

14- M. Manzano, M. Vallet-Regí, Mesoporous silica nanoparticles in nanomedicine applications, Journal of Materials Science: Materials in Medicine, 2018, 29(5), 65.

15- Y. Song, Y. Li, Q. Xu, Z. Liu, Mesoporous silica nanoparticles for stimuli-responsive controlled drug delivery: Advances, challenges, and outlook, International Journal of Nanomedicine, 2017, 12, 87-110.

16- P.N. Diagboya, E.D. Dikio, Silica-based mesoporous materials; emerging designer adsorbents for aqueous pollutants removal and water treatment, Microporous and Mesoporous Materials, 2018, 266, 252-267.

17- P. Cheyssac, M. Klotz, E. Søndergård, Optical properties of ordered mesoporous layers of silica, Thin Solid Films, 2006,495(1-2), 237-242.

18- J. Miguel, J. Mateos, L.C. Quintero, C. Rial, Characterization of petroleum bitumens and their fractions by thermogravimetric analysis and differential scanning calorimetry, Fuel, 1996, 75(15), 1691-1700.

19- G. Boczkaj, A. Przyjazny, M. Kamin, Characteristics of volatile organic compounds emission profiles from hot road bitumens, Chemosphere, 2014, 107, 23-30. 
20- L.T. Gibson, Mesosilica Materials and Organic Pollutant Adsorption: Part A Removal from Air, Chemical Society Reviews, 2014, 43, 5163-5172.

21- H. A. Barnes, J. F. Hutton, Walters, K. An introduction to rheology, Elsevier Science, 1989, 198.

22- C. Oliviero Rossi, P. Caputo, V. Loise, D. Miriello, B. Teltayev, R. Angelico, Role of a food grade additive in the high temperature performance of modified bitumens, Colloids and Surfaces A: Physicochem. Eng. Aspects, 2017, 592, 618-624.

23- E.I. Szerb, I. Nicotera, B. Teltayev, R. Vaiana, C. Oliviero Rossi, Highly stable surfactantcrumb rubber-modified bitumen: NMR and rheological investigation, Road Materials and Pavement Design, 2017, 19(5), 1192-1202.

24- S.S. Idris, N.A. Rahman, K. Ismail, A.B. Alias, Z.A. Rashid, M.J. Aris, Investigation on thermochemical behaviour of low rank Malaysian coal, oil palm biomass and their blends during pyrolysis via thermogravimetric analysis (TGA), Bioresource Technology, 2010, 101, 4584-4592.

25- R.E. Zacharia, S.L. Simon, Dynamic and Isothermal Thermogravimetric Analysis of a Polycyanurate Thermosetting System, Polymer engineering and science, 1998, 38(4), 566-572.

26- Determination by Solid-phase Microextraction/Gas Chromatography/Mass Spectrometry of Polycyclic Aromatic Hydrocarbons in Bitumen Fumes During Road Pavingy, J. Mass Spectrom, 1999, 34, 1383-1384.
27- A. Bouaid, L. Ramos, M.J. Gonzalez, P. Fernàndez, C. Càmara, Solid-phase microextraction method for the determination of atrazine and four organophosphorus pesticides in soil samples by gas chromatography, Journal of Chromatography A, 2001, 939, 13-21.

28- N. Baldino, D. Gabriele, C. Oliviero Rossi, L. Seta, F.R. Lupi, P. Caputo, Low temperature rheology of polyphosphoric acid (PPA) added bitumen, Construction and Building Materials, 2012, 36, 592-596.

29- N. Baldino, D. Gabriele, F.R. Lupi, C. Oliviero Rossi, P. Caputo, T. Falvo, Rheological effects on bitumen of polyphosphoric acid (PPA) addition, Construction and Building Materials, 2013, 40, 397-404.

30- G. Polacco, S. Berlincioni, D. Biondi, J. Stastna, L. Zanzotto, Asphalt modification with different polyethylene-based polymers, European Polymer Journal, 2005, 41, 2831-2844.

31- C. Oliviero Rossi, A. Spadafora, B. Teltayev, G. Izmailova, Y. Amerbayev, V. Bortolotti, Polymer modified bitumen: Rheological properties and structural characterization, Colloids and Surfaces. A, Physicochemical and Engineering aspects, 2015, 480, 390-397.

32- F.J. Navarro, P. Partal, F.J. X Martınez-Boza, C. Gallegos, Influence of processing conditions on the rheological behavior of crumb tire rubber-modified Bitumen, Journal of Applied Polymer Science, 2007, 104, 1683-1691. 